\title{
CARACTERIZAÇÃO AGRONÔMICA E MOLECULAR DE GENÓTIPOS DIPLÓIDES MELHORADOS DE BANANEIRA ${ }^{1}$
}

\author{
EDSON PERITO AMORIM ${ }^{2}$, LAURO SARAIVALESSA ${ }^{3}$, CARLOS ALBERTODA SILVALEDO $^{2}$, \\ VANUSIA BATISTA DE OLIVEIRAAMORIM ${ }^{4}$, RONALDO VIANADOS REIS $^{5}$,

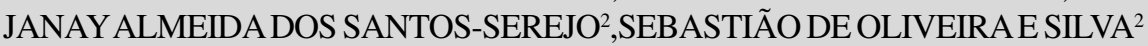

RESUMO - Uma investigação sobre a diversidade genética entre 11 diplóides melhorados de bananeira, por meio de nove características agronômicas e 16 marcadores microssatélites, foi implementada na Embrapa Mandioca e Fruticultura Tropical, Cruz das Almas (BA), Brasil. A distância generalizada de Mahalanobis indicou alto grau de divergência genética. Os genótipos foram agrupados em três grupos. As características altura de planta, número de pencas, número de frutos e diâmetro do pseudocaule contribuíram com grande parte da divergência genética observada. O número de alelos obtidos foi 120, com média de 7,51 alelos por primer. A similaridade genética média foi de 0,44 , variando de 0,29 a 0,60 . Novas combinações parentais podem ser identificadas com base na divergência entre estes diplóides, contribuindo para o desenvolvimento de novos diplóides melhorados, evitando o estreitamento da base genética e disponibilizando nova variabilidade genética para a seleção.

Termos para Indexação: Musa sp., divergência genética, microssatélites, híbridos, Mahalanobis.

\section{AGRONOMIC AND MOLECULAR CHARACTERIZATION OF DIPLOID IMPROVED BANANA GENOTYPES}

\begin{abstract}
An investigation about the genetical diversity among eleven banana diploid genotypes using nine agronomical characteristics and sixteen microsatellite markers was implanted at Embrapa Cassava and Tropical Fruits, Cruz das Almas (BA), Brazil. The generalized distance of Mahalanobis indicated the presence of genetic diversity. The genotypes were grouped into tree clusters. Among the investigated characteristics, the plant height, number of bunch's, number of fruits per bunch and pseudostem exhibited high contribution towards genetic divergence. The average number of alleles per primer was 7.51, with a total of 120 alleles identified. The average similarity among the all diploid was 0.44 , range from 0.29 up to 0.60 . New parental combinations can be identified with base of the divergence between these diploids, contributing for development of new improved diploids preventing the narrow genetic base and creating new genetic variability for selection.
\end{abstract}

Index terms: Musa sp., genetic divergence, microsatellites, hybrids, Mahalanobis.

\section{INTRODUÇÃO}

A banana é a segunda fruta mais consumida no Brasil, perdendo apenas para a laranja. Em relação ao seu papel social, a cultura é explorada por pequenos empresários rurais, permitindo a fixação de mão-de-obra no campo, uma vez que se constitui em fonte de renda contínua para estes agricultores (Mascarenhas, 1997).

Os programas de melhoramento de bananeira têm gerado híbridos tetraplóides promissores, obtidos a partir dos cruzamentos entre cultivares triplóides e diplóides melhorados ou selvagens, que apresentam características agronômicas de interesse, entre as quais: porte reduzido, resistência a pragas e qualidade físico-química dos frutos (Silva et al., 2005).

A caracterização agronômica de diplóides e a estimativa da variabilidade genética disponível para o melhoramento são informações úteis, tanto na escolha de progenitores para cruzamentos entre

\footnotetext{
'(Trabalho 062-08). Recebido em: 18-03-2008. Aceito para publicação em: 09-09-2008.

${ }^{2}$ Pesquisador(a) A, Dr(a). Embrapa Mandioca e Fruticultura Tropical. Rua Embrapa, s/n ${ }^{\circ}$ - Cruz das Almas-BA - CEP 44380000. E-mail: edson@cnpmf.embrapa.br, ledo@cnpmf.embrapa.br, janay@cnpmf.embrapa.br, ssilva@cnpmf.embrapa.br. ${ }^{3} \mathrm{Eng}^{\circ}$. Agro. M.Sc. Embrapa Acre, BR 364, km 14, Rio Branco-AC - Caixa postal 321, CEP 69908-970, laurolessa@yahoo.com.br.

${ }^{4}$ Pesquisadora, Dra. Universidade Estadual de Campinas, Instituto de Biologia, Departamento de Genética e Evolução, Campinas-SP - CEP 13083-970. E-mail: vanusia@unicamp.br.

${ }^{5}$ Eng $^{\circ}$. Agro ${ }^{\circ}$. Universidade Estadual de Montes Claros, Montes Claros (MG), CEP: 39401-089. E-mail: ronasviana@yahoo.com.br.
} 
genótipos divergentes, visando a explorar a heterose e desenvolver novos diplóides melhorados, quanto no cruzamento destes com triplóides, com o objetivo de obter novos híbridos tetraplóides de banana.

Vários marcadores moleculares, em especial aqueles associados com métodos baseados em PCR (Polymerase Chain Reaction), incluindo AFLP (Amplified Fragment Lenght Polymorphism), RAPD (Random Amplified Polymorphic DNA) e microssatélites ou SSR (Simple Sequence Repeats), têm sido amplamente utilizados na estimativa da variabilidade genética e em estudos filogenéticos em banana (Creste, 2002; Creste et al., 2003; Creste et al., 2004; Ning et al., 2007; Wang et al., 2007; Nsabimana \& Staden, 2007).

O objetivo deste trabalho foi estimar a divergência genética entre 11 diplóides melhorados de bananeira utilizados pelo programa de melhoramento de banana da Embrapa Mandioca e Fruticultura Tropical, por meio de características agronômicas e marcadores moleculares microssatélites.

\section{MATERIAL E MÉTODOS}

Foram utilizados onze diplóides melhorados de bananeira desenvolvidos pelo programa de melhoramento genético da Embrapa Mandioca e Fruticultura Tropical, exceção ao diplóide SH3263 desenvolvido pela Fundacion Hondureña de Investigación Agrícola (FHIA), em Honduras. Esses diplóides são utilizados como doadores de pólen na obtenção de cultivares tetraplóides. Informações sobre cada genótipo encontram-se na Tabela 1.

\section{Caracterização agronômica}

$\mathrm{O}$ experimento foi conduzido no campo experimental da Embrapa Mandioca e Fruticultura Tropical, em Cruz das Almas (BA). Os genótipos foram dispostos em blocos casualizados, com quatro repetições. Cada parcela constituiu-se de seis plantas, espaçadas 2,5m na linha e 2,5m na entrelinha. Avaliaram-se durante o período de floração e antes da colheita os seguintes caracteres: a) Altura de plantas (APL - cm): medida realizada no momento da emissão do cacho com o auxílio de uma régua posicionada desde o nível do solo até o ponto de saída do engaço; b) Diâmetro do pseudocaule (DPC - cm): medida realizada no momento da emissão do cacho com o auxílio de um paquímetro de madeira posicionado a $30 \mathrm{~cm}$ do solo; c) Número de filhos na floração (NFI): contou-se, na época de florescimento de cada planta, o número de mudas produzidas junto ao genótipo avaliado; d) Número de folhas na floração (NFL): contou-se o número de folhas vivas presentes nas plantas na época de florescimento, considerando-se como funcional a folha que possuísse $50 \%$ ou mais de seu limbo verde; e) Ciclo da planta do plantio à emissão (CIC - dias): anotouse, para cada planta útil da parcela, a data do dia da antese da primeira penca do cacho, podendo, então, calcular o número de dias do plantio ao florescimento; f) Número de pencas (NPE): 70 dias após a data de floração, procedeu-se à contagem do número de pencas por cacho de cada genótipo na parcela útil; g) Número de frutos (NFR): 70 dias após a data de floração, procedeu-se ainda à contagem do número de frutos por cacho de cada genótipo na parcela útil; h) Sigatoka Amarela (SIA): avaliou-se a presença de Sigatoka Amarela aos 100 dias após a emissão do cacho de cada genótipo presente na parcela útil. Para isso utilizou-se da escala de notas que varia de 0 a 10 , onde 0 - planta sem sintomas e 10 - planta com folhas velhas e novas bastante atacadas; i) Comprimento do fruto (CFR - cm): 70 dias após o florescimento, procedeu-se à mensuração do comprimento médio dos frutos com o auxílio de uma fita métrica. Nesse caso, avaliou-se somente o comprimento do fruto sem pedicelo.

\section{Análise dos dados agronômicos}

Os dados foram submetidos à análise de variância, e as médias, agrupadas pelo teste de Scott \& Knott (1974) a 5\%. Foram estimadas as distâncias generalizadas de Mahalanobis, entre os 11 diplóides melhorados de bananeira, considerando as nove características agronômicas. Utilizou-se, também, o critério de Singh (1981) para quantificar a contribuição relativa desses caracteres para a divergência genética. Tanto a análise de variância quanto as estimativas das distâncias generalizadas de Mahalanobis foram realizadas, utilizando-se do aplicativo estatístico-computacional Genes (Cruz, 2006).

\section{Caracterização molecular via microssatélites ou SSR}

Um total de 16 pares de primers foram utilizados, sendo seis pertencentes à série Ma, desenvolvida por Crouch et al. (1998); cinco pares da série AGMI, desenvolvidos por Lagoda et al. (1998); três da série MaOCEN, obtidos por Creste et al. (2006); um primer (STMS 1), obtido por Kaemmer et al. (1997), e um primer (Mb 1-100), descrito por Oriero et al. (2006) (Tabela 2). 


\section{Extração de DNA e condições de PCR}

DNA genômico foi extraído de folhas jovens, utilizando o método CTAB (Doyle \& Doyle, 1990). A avaliação da quantidade e qualidade do DNA foi efetuada mediante análise comparativa das amostras em gel de agarose $0,8 \%$, corado com brometo de etídio, sendo as amostras diluídas em água ultrapura e padronizadas em $10 \mathrm{ng} \cdot \mu \mathrm{L}^{-1}$.

As reações de amplificação via SSRs foram completadas para o volume final de $13 \mu \mathrm{L}$, contendo: $\mathrm{KCl} 50 \mathrm{mM}$, Tris-HCl $10 \mathrm{mM}$ (pH 8,3), $\mathrm{MgCl}_{2} 2,5$ $\mathrm{mM}, 100 \mu \mathrm{M}$ de cada um dos dNTPs (dATP, dTTP, dGTP, dCTP), 0,2 $\mu \mathrm{M}$ de cada primer, 50 ng de DNA genômico e uma Unidade de Taq DNA polimerase (Pharmacia Biotech, EUA).

As amplificações foram conduzidas em termociclador Perkin Elmer modelo 9700, empregandose o esquema de touchdown com ciclo inicial de $3 \mathrm{~min}$ a $94^{\circ} \mathrm{C}$, seguido de $40 \mathrm{~s}$ a $94^{\circ} \mathrm{C}, 40 \mathrm{~s}$ a $55^{\circ} \mathrm{C}$, reduzindo um grau a cada ciclo, 1 min a $72^{\circ} \mathrm{C}$, num total de 10 ciclos, seguido de 25 ciclos de 40 s a $94^{\circ} \mathrm{C}$, 40 s a $45^{\circ} \mathrm{C}$ e 60 s a $72^{\circ} \mathrm{C}$.

\section{Eletroforese e detecção do polimorfismo}

Os fragmentos foram separados em géis de poliacrilamida desnaturante $(6 \%$ poliacrilamida, $8 \mathrm{M} \mathrm{de}$ uréia) sob condições-padrão, e os produtos da amplificação foram corados com nitrato de prata para a visualização dos alelos, seguindo metodologia descrita por Creste et al. (2001).

\section{Análise dos dados moleculares}

Os fragmentos amplificados foram avaliados como ausência (0) e presença (1). A similaridade genética entre todos os onze genótipos foi calculada a partir do coeficiente de Dice. As similaridades genéticas foram utilizadas para fazer o agrupamento dos genótipos pelo método UPGMA (Unweighted Pair-Group Method Averages) por meio do software NTSYSpc (Rohlf, 2000). Foi calculado o valor de correlação cofenética entre a matriz de similaridades genéticas e a matriz dos valores cofenéticos, a fim de verificar a consistência do agrupamento.

\section{RESULTADOS E DISCUSSÃO}

Constatou-se que houve diferenças significativas entre as médias dos genótipos de banana em todas as características avaliadas, exceção ao número de folhas (NFL). O coeficiente de variação oscilou de 5,30\% (APL) a 22,12\% (NFI) (Tabela 3).

A altura de planta (APL) variou de $162,2 \mathrm{~cm}$ para o diplóide $8694-20$ a 254,7 cm para o diplóide SH3263, com média de 208,6 cm. Comportamento semelhante foi observado para o diâmetro do pseudocaule, onde o diplóide SH3263 apresentou maior valor (Tabela 3). A identificação de diplóides com baixa estatura é importante, uma vez que esses genótipos serão utilizados como progenitores masculinos no cruzamento com triplóides, visando ao desenvolvimento de tetraplóides com boas características agronômicas, entre as quais o porte baixo (Leite et al., 2003).

A média para número de filhos na floração (NFI) foi de 4,7, variando de 2,1 para o diplóide 898701 a 8,2 para o 0323-03. Em relação ao número de folhas (NFL), a média observada foi de 10,9, não se observando diferenças significativas entre os onze genótipos. Todos os diplóides apresentaram um número de folhas acima do mínimo considerado para a cultura, que é de oito (Soto Ballestero, 1992).

$\mathrm{O}$ ciclo do plantio à emissão (CIC) teve variação de 109 dias entre o menor e o maior valor, com média de 349 dias. Os diplóides melhorados com maior precocidade foram o TH0301 e o 8694-20, e os mais tardios, os genótipos 4223-06 e SH3263. A precocidade é uma característica de grande importância para a bananeira, e o desenvolvimento de diplóides com reduzido intervalo entre o plantio e a emissão da inflorescência faz-se necessário (Silva et al., 2002). Neste trabalho, foram identificados diplóides precoces, com ciclo médio de 300 dias.

Em relação aos componentes de produção: número de pencas (NPE), número de frutos (NFR) e comprimento do fruto (CFR), o genótipo com maior destaque foi o SH3263, seguido dos diplóides 011601 e 1304-06 (Tabela 3). Essas características são importantes, pois estão associadas com o peso final do cacho, que é a unidade comercial (Silva et al., 2005).

Em relação ao comportamento dos diplóides frente à Sigatoka-amarela, percebe-se que todos podem ser classificados como resistentes à doença, em função da pequena área foliar atacada pelo patógeno, com nota média de 3,1 (Tabela 3).

A distância generalizada de Mahalanobis permitiu separar os genótipos em três grandes grupos. No grupo I, estão incluídos os diplóides melhorados 4279-06, 8694-20, 9179-03, 8987-01, TH0301, 1318-01, 0323-03, 4223-06; no grupo II, os diplóides 0116-01 e 1304-06 e, no grupo III, apenas o diplóide SH3263.

A comparação das médias, para as nove características em estudo, e os grupos obtidos, 
por meio da distância de Mahalanobis, permitem inferir sobre diferenças entre os três grupos (Tabela 3). No grupo I, estão presentes genótipos com menores valores para número de pencas, frutos e comprimento de frutos. No grupo II, estão presentes diplóides com valores intermediários para as características mencionadas anteriormente. O diplóide SH3263 (grupo III) foi o genótipo com maiores valores para NPE, NFR e CFR, porém apresentou porte alto e ciclo do plantio à emissão longo.

A análise utilizando o critério de Singh (1981), para estimar a contribuição relativa de cada característica para a expressão da divergência genética, indicou que os caracteres APL $(22,80 \%)$, NPE (26,04\%), DPC (12,04\%) e o NFR (12,26\%), foram os que mais contribuíram para a divergência total entre os 11 genótipos de banana (73,14\%) (Tabela 4).

Por meio da razão entre o $\mathrm{CV}_{\mathrm{g}} \mathrm{e} \mathrm{CV}$ maior que a unidade, infere-se pela facilidade na seleção para os caracteres APL, DPC, NFI, CIC, NPE e NFR. Além disso, as suas altas herdabilidades também contribuem para a seleção. A importância das outras características foi comparativamente menor.

O número de alelos obtidos foi 120 , com média de 7,51 alelos por primer. O maior número de alelos foi identificado nos primers MaOCEN 03 e AGMI 103 (11 alelos), e o menor número, no primer STMS 7 (3 alelos) (Tabela 2). O número médio de alelos por loco SSR é similar ao obtido com outros estudos realizados em banana (Creste et al., 2003; Creste et al., 2004; Creste et al., 2006; Ning et al., 2007). Ning et al. (2007) consideraram suficientes dez SSR para genotipar 50 acessos de banana de diferentes origens, encontrando 92 alelos; Creste et al. (2004) utilizaram nove SSRs para genotipar 49 diplóides a partir de 115 alelos, e Creste et al. (2003) genotiparam 35 cultivares de banana com 11 SSRs e 67 alelos. Dessa forma, conclui-se que o número de marcadores microssatélites utilizados neste estudo foi suficiente para a estimativa da variabilidade genética entre os 11 diplóides de banana.

O conteúdo de informação de polimorfismo (PIC) variou de 0,35 para o primer STMS 7 a 0,88 para o primer Ma 3-103, com média de 0,77.

$\mathrm{O}$ dendrograma das similaridades genéticas baseada em SSR, obtido pelo método UPGMA, encontra-se na Figura 1. O valor cofenético foi alto ( $\mathrm{r}$ $=0,70, \mathrm{P}<0,0001,10.000$ permutações) e adequado, já que r $\geq 0,56$ é considerado ideal, refletindo uma boa concordância com os valores de similaridade genética (Vaz Patto et al., 2004).

A similaridade genética média entre todos os diplóides foi 0,44 , variando de 0,29 entre os diplóides
SH3263 e 4279-06 a 0,60 entre os genótipos 8694-20 e 0323-03, indicando a existência de ampla variabilidade genética entre os genótipos.

Neste trabalho, assumiu-se como ponto de corte no dendrograma a similaridade genética média entre todos os diplóides genotipados com microssatélites $(0,44)$. Com base neste ponto de corte, foram formados três grupos: G1-com os genótipos 131801, SH3263, 0116-01, 1304-06 e 9179-03; G2-com os diplóides 0323-03, 8694-20 e 4223-06; G3-os diplóides 4279-06, TH0301 e 8987-01 (Figura 1).

A comparação entre os resultados obtidos, por meio da caracterização agronômica e molecular, obtida no módulo MXCOMP do aplicativo NTSYS, apresentou uma correção negativa não-significativa $\mathrm{e}$ de baixa magnitude $[\mathrm{r}=-0,15, \mathrm{P}>0,85,10.000$ permutações, pelo teste de Mantel (1967)]. Dessa forma, os resultados obtidos por meio da caracterização agronômica e molecular não apresentaram concordâncias.

Souza e Sorrells (1991) sugerem que a baixa associação entre dados morfológicos e moleculares pode ter por base a parcial e insuficiente representação do genoma quando são utilizados dados morfológicos. Essa baixa correlação também pode ser explicada pela ausência de associação entre os locos que controlam os caracteres morfológicos estudados e os alelos identificados por meio de marcadores SSR, uma vez que a correlação será tão maior quanto maior for esta associação.

Koehler-Santos et al. (2003) não encontraram concordâncias no padrão de variação em germoplasma de cítrus, quando compararam as matrizes geradas com dados morfológicos e marcadores SSR. Resultado semelhante foi encontrado por Oliveira (2005) utilizando marcadores SSR e descritores morfoagronômicos para caracterizar acessos de Açaí.

Outro fator que dificulta a existência de associação entre dados morfológicos e moleculares é o fato de grande parte da variação detectada pelos marcadores moleculares ser do tipo não-adaptativa e, portanto, não-sujeita à seleção, ao contrário dos caracteres fenotípicos que são sujeitos tanto à seleção natural quanto artificial, além da grande influência ambiental sobre a manifestação destes caracteres (Vieira et al., 2005). 
TABELA 1 - Genealogia de onze diplóides melhorados de bananeira do grupo genômico AA utilizados pelo programa de melhoramento genético da Embrapa Mandioca e Fruticultura Tropical. Cruz das Almas, 2008.

\begin{tabular}{cl}
\hline Diplóide $^{1}$ & \\
\hline $4279-06$ & M53 x 2803 (Tuu Gia x Calcutta) \\
TH03-01 & Terrinha x Calcutta \\
$8987-01$ & 1318-01 (Malaccensis x Sinwobogi) x 0338-01(Calcutta x Heva) \\
$0323-03$ & Calcutta (M. acuminata spp. burmannica) x Cultivar sem nome \\
$1318-01$ & Malaccensis FHIA x Sinwobogi \\
$0116-01$ & Borneo x Guyod \\
$8694-20$ & 0337-02 (Calcutta x Galeo) x SH32-63 \\
$1304-06$ & Malaccensis x Madang (Musa acuminata spp. banksii) \\
$9179-03$ & 0116-01 (Borneo x Guyod)x 2803 (Tuu Gia x Calcutta) \\
$4223-06$ & M53 x Cultivar sem nome n 2 \\
SH32-63 & Híbrido selecionado em Honduras \\
\hline
\end{tabular}

${ }^{1}$ Os dois primeiros números referem-se ao genitor feminino, os dois seguintes ao genitor masculino e os dois últimos ao número da seleção.

TABELA 2 - Locos microssatélites (SSR), seqüência repetida, número de alelos e conteúdo e informação de polimorfismo (PIC). Cruz das Almas, 2008.

\begin{tabular}{|c|c|c|c|}
\hline Locos SSR & Repetição (F / R) & Alelos & PIC \\
\hline AGMI $103-103$ & cagaatcgctaaccetatcctca / ccetttgcgtgccectaa & 11 & 0,83 \\
\hline AGMI 187-188 & gcaactttggcagcatttt / tgatggactcatgtgtacctactat & 7 & 0,80 \\
\hline AGMI $24-25$ & tttgatgtcacaatggtgttcc / taaaggtgggttagcattagg & 9 & 0,85 \\
\hline AGMI 67-68 & ataccttctccegttcttcttc / tggaaacccaatcattgatc & 9 & 0,81 \\
\hline AGMI 95-96 & acttattceceggactcaa / actctcgeccatcttcatcc & 4 & 0,69 \\
\hline Ma 2-7 & tgaatcccaagtttggtcaaga / caactcttgtccetcacttca & 5 & 0,76 \\
\hline Ma 1-17 & aggcggggaatcggtaga / ggcgggagacagatggagt & 7 & 0,83 \\
\hline Ma 1-24 & gagcccattaagctgaaca / ccgacagtcaacatacaataca & 7 & 0,81 \\
\hline Ma 1-27 & tgaatcccaatttggtcaag / caaaacactgtccccatctc & 9 & 0,87 \\
\hline Ma 3-103 & tcgectctctttagctctg / tgttggaggatctgagattg & 10 & 0,88 \\
\hline Ma 3-90 & gcacgaagaggcatcac / ggccaaatttgatggact & 7 & 0,65 \\
\hline MaOCEN 01 & tctcaggaagggcaatc / ggaccaaagggaaagaaacc & 5 & 0,75 \\
\hline MaOCEN 03 & ggaggaaatggaggtcaaca / ttcgggataggaggaggag & 11 & 0,76 \\
\hline MaOCEN 13 & getgctattttgtcettggtg / cttgatgetgggaatctgg & 8 & 0,86 \\
\hline $\mathrm{Mb} 1-100$ & tcggctggctaatagaggaa / tctcgagggatggtgaaaga & 8 & 0,78 \\
\hline STMS 7 & aagaaggcacgagggtag / cgaaccaagtgaaatagcg & 3 & 0,35 \\
\hline Total & & 120 & \\
\hline Média & & 7,51 & 0,77 \\
\hline
\end{tabular}

TABELA 3 - Médias de nove caracteres agronômicos avaliados em 11 diplóides melhorados de bananeira. Cruz das Almas, 2008.

\begin{tabular}{|c|c|c|c|c|c|c|c|c|c|}
\hline \multirow{2}{*}{ Genótipos } & \multicolumn{7}{|c|}{ Características Agronômicas } & \multirow[b]{2}{*}{ SIA } & \multirow[b]{2}{*}{ CFR } \\
\hline & APL & DPC & NFI & NFL & $\mathrm{CIC}$ & NPE & NFR & & \\
\hline $4279-06$ & $190,7 \mathrm{c}$ & $14,2 \mathrm{~b}$ & $3,8 b$ & $10,0 \mathrm{a}$ & $360 \mathrm{~b}$ & $5,2 \mathrm{c}$ & $88,7 \mathrm{~d}$ & $3,2 \mathrm{a}$ & $10,2 b$ \\
\hline TH0301 & $183,5 \mathrm{c}$ & $12,7 b$ & $4,2 b$ & 12,5 & $301 b$ & $5,7 \mathrm{c}$ & $63,7 \mathrm{e}$ & $3,5 \mathrm{a}$ & $12,7 \mathrm{a}$ \\
\hline 8987-01 & $182,7 \mathrm{c}$ & $13,0 \mathrm{~b}$ & $2,1 b$ & 12,0 & $339 b$ & $6,0 \mathrm{c}$ & $97,7 d$ & $3,0 \mathrm{a}$ & $10,5 b$ \\
\hline $0323-03$ & $222,5 b$ & $14,7 b$ & $8,2 \mathrm{a}$ & 10,7 & $356 \mathrm{~b}$ & $6,0 \mathrm{c}$ & $84,2 \mathrm{~d}$ & $3,5 \mathrm{a}$ & $10,7 b$ \\
\hline $1318-01$ & $211,2 b$ & $13,2 b$ & $4,9 b$ & 12,2 & $335 b$ & $6,2 \mathrm{c}$ & $103,5 d$ & $3,5 \mathrm{a}$ & $12,7 \mathrm{a}$ \\
\hline 0116-01 & $213,2 b$ & $13,0 \mathrm{~b}$ & $3,8 b$ & 10,2 & $341 b$ & $9,2 \mathrm{~b}$ & $149,0 \mathrm{~b}$ & $3,2 \mathrm{a}$ & $10,2 b$ \\
\hline $8694-20$ & $162,2 \mathrm{~d}$ & $14,0 \mathrm{~b}$ & $4,3 b$ & 10,2 & $319 b$ & $6,0 \mathrm{c}$ & $97,0 \mathrm{~d}$ & $3,5 \mathrm{a}$ & $10,7 b$ \\
\hline 1304-06 & $237,7 \mathrm{a}$ & $14,2 \mathrm{~b}$ & $5,1 b$ & 9,2 & $349 b$ & $9,2 \mathrm{~b}$ & $154,0 \mathrm{~b}$ & $3,2 \mathrm{a}$ & $11,2 \mathrm{~b}$ \\
\hline $9179-03$ & $185,2 \mathrm{c}$ & $14,0 \mathrm{~b}$ & $4,4 b$ & 11,5 & $329 b$ & $7,0 \mathrm{c}$ & $127,7 \mathrm{c}$ & $3,5 \mathrm{a}$ & $9,5 \mathrm{~b}$ \\
\hline $4223-06$ & $251,0 \mathrm{a}$ & $13,5 b$ & $6,9 a$ & 10,2 & $410 \mathrm{a}$ & $6,2 \mathrm{c}$ & $96,0 \mathrm{~d}$ & $2,2 b$ & $12,0 \mathrm{a}$ \\
\hline SH3263 & $254,7 \mathrm{a}$ & $19,5 \mathrm{a}$ & $3,9 b$ & 10,7 & $410 \mathrm{a}$ & $11,2 \mathrm{a}$ & $192,7 \mathrm{a}$ & $2,0 \mathrm{~b}$ & $11,7 \mathrm{a}$ \\
\hline F (Tratamentos) & $30,5^{*}$ & $21,4^{*}$ & $9,7^{*}$ & 2,9 ns & $6,39 *$ & $51,1^{*}$ & $47,3^{*}$ & $3,2^{*}$ & $4,2 *$ \\
\hline CV $(\%)$ & 5,3 & 5,7 & 22,1 & 11,1 & 7,65 & 7,5 & 9,6 & 18,7 & 9,3 \\
\hline Média geral & 208,6 & 14,2 & 4,7 & 10,9 & 349 & 7,1 & 114,0 & 3,1 & 11,1 \\
\hline
\end{tabular}

APL: altura de planta $(\mathrm{cm})$, DPC: diâmetro do pseudocaule $(\mathrm{cm})$, NFI: número de filhos na floração, NFL: número de folhas, CIC: ciclo do plantio a emissão (dias), NPE: número de pencas, NFR: número de frutos, SIA: Sigatoka-amarela, CFR:

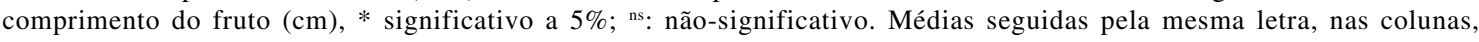
pertencem ao mesmo grupo, pelo teste de agrupamento de Scott e Knott (1974), a 5\% de probabilidade. 
TABELA 4 - Importância relativa de nove caracteres agronômicos para estudo da diversidade genética entre 11 diplóides melhorados de bananeira, segundo critério de Singh (1981), e parâmetros associados a estas características. Cruz das Almas, 2008.

\begin{tabular}{crrcrc}
\hline Características & \multicolumn{1}{c}{$S . j$} & \multicolumn{1}{c}{$S_{j} j_{(\%)}$} & Herdabilidade & $C V_{g}$ & $C V_{g} / C V_{e}$ \\
\hline APL & 1327,07 & 22,80 & 96,72 & 14,38 & 2,71 \\
DPC & 700,49 & 12,04 & 95,34 & 12,83 & 2,26 \\
NFI & 448,64 & 7,71 & 89,72 & 32,67 & 1,47 \\
NFL & 197,98 & 3,40 & 66,10 & 7,75 & 0,70 \\
CIC & 223,61 & 3,84 & 84,35 & 8,88 & 1,16 \\
NPE & 1515,82 & 26,04 & 98,04 & 26,70 & 3,54 \\
NFR & 713,96 & 12,26 & 97,88 & 32,75 & 3,40 \\
SIA & 77,32 & 1,33 & 69,37 & 14,04 & 0,75 \\
CFR & 165,25 & 2,84 & 76,32 & 8,33 & 0,90 \\
\hline
\end{tabular}

S.j: contribuição da variável $x$ para o valor da distância de Mahalanobis entre os genótipos $i$ e $i$, $\mathrm{CV}_{\mathrm{g}}$ : coeficiente de variação genética, $\mathrm{CV}_{\mathrm{e}}$ : coeficiente de variação ambiental, APL: altura de planta $(\mathrm{cm})$, DPC: diâmetro do pseudocaule $(\mathrm{cm}), \mathrm{NFI}$ : número de filhos na floração, NFL: número de folhas, CIC: ciclo do plantio à emissão (dias), NPE: número de pencas, NFR: número de frutos, SIA: Sigatoka-amarela, CFR: comprimento do fruto $(\mathrm{cm})$.

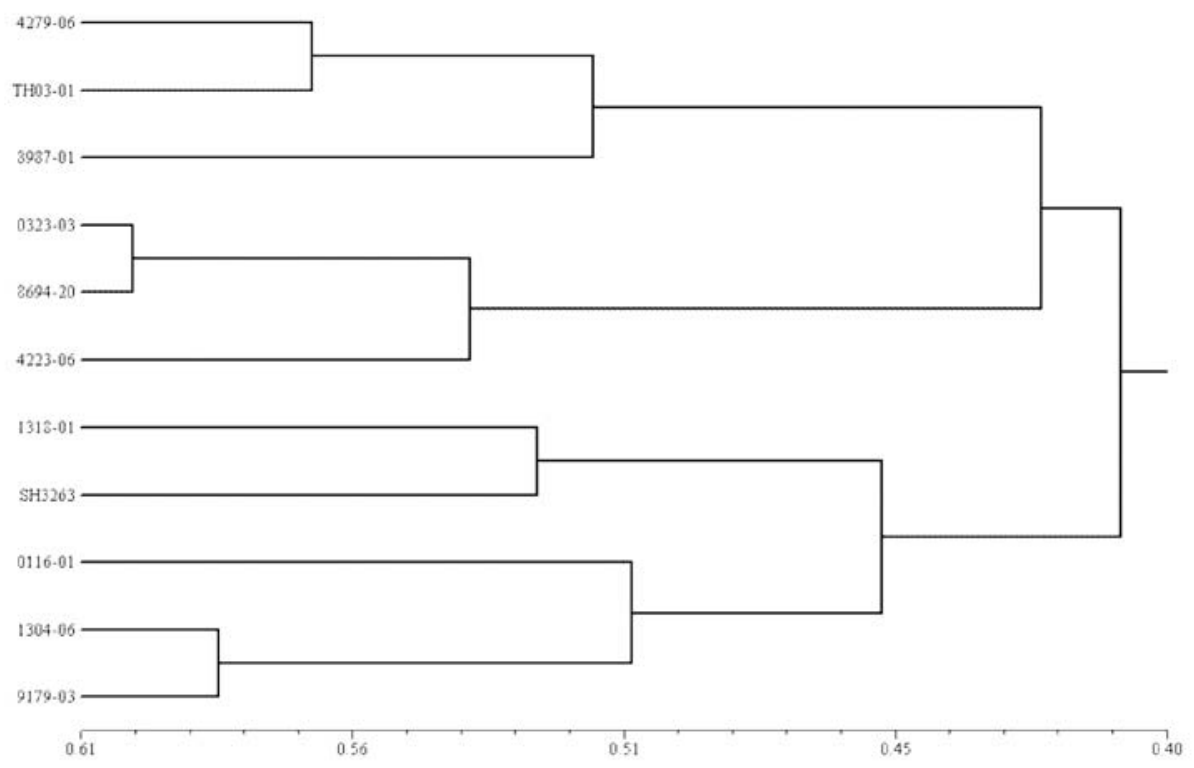

FIGURA 1 - Similaridade genética entre 11 diplóides melhorados de bananeira obtida a partir de 16 marcadores moleculares microssatélites. Cruz das Almas, 2008.

\section{CONCLUSÕES}

1- Existe variabilidade genética suficiente para o desenvolvimento de novos diplóides com características agronômicas desejáveis.

2- As características altura de planta, número de pencas, número de frutos por penca e diâmetro do pseudocaule contribuem com grande parte da variabilidade genética entre os 11 diplóides melhorados de banana.
3-Não há concordância entre os agrupamentos formados com base nos caracteres agronômicos e marcadores microssatélites.

4 - É possível selecionar novas combinações parentais visando ao desenvolvimento de novos diplóides melhorados que apresentem, concomitantemente, porte baixo (diplóide 8694-20), ciclo precoce (diplóide TH0301), elevado número e tamanho dos frutos (diplóide 1304-06) e resistência à Sigatoka-amarela. 


\section{REFERÊNCIAS}

CRESTE, S. Avaliação da variabilidade genética em Musa spp. utilizando marcadores microssatélites. 2002. 86 f. Tese (Doutorado em Agronomia) - Escola Superio9r de Agricultura "Luiz de Queiroz", Universidade de São Paulo, Piracicaba, 2002.

CRESTE, S.; BENATTI, T.; ORSI, M.R.; RISTERUCCI, A.M.; FIGUEIRA, A. Isolation and characterization of microsatellite loci from a commercial cultivar of Musa acuminata. Molecular Ecology Notes, Oxford, v. 6, n.2, p.303-306, 2006.

CRESTE, S.; NETO, A.T.; VENCOVSKY, R.; SILVA, S.O.; FIGUEIRA, A. Genetic diversity of Musa diploid and triploid accessions from the Brazilian banana breeding program estimated by microsatellite markers. Genetic Resources and Crop Evolution, Dordrecht, v.51, n.7, p.723-733, 2004.

CRESTE, S.; TULMANN NETO, A.; FIGUEIRA, A. Detection of single sequence repeats polymorphisms in denaturing polyacrylamide sequencing gel by silver staining. Plant Molecular Biology Reporter, Athens, v.19, n.4, p.299-306, 2001.

CRESTE, S.; TULMANN NETO, A.; SILVA, S.O.; FIGUEIRA, A. Genetic characterization of banana cultivars (Musa spp.) from Brazil using microsatellite markers. Euphytica, Wageningen, v.132, n.3, p.259268, 2003.

CROUCH, H.K.; CROUCH, J.H.; JARRET, R.L. et al. Segregation at microsatellite loci in haploid and diploid gametes of Musa. Crop Science, Madison, v.38, n.1, p.211-217, 1998.

CRUZ, C. D. Programa genes: análise multivariada e simulação. Viçosa: UFV, 2006. 175p.

DOYLE, J.J.; DOYLE, J.L. Isolation of plant DNA from fresh tissue. Focus, Rockville, v.12, n.1, p.1315,1990 .

KAEMMER, D.; FISCHER, D.; JARRET, R.L.; BAURENS, F.C.; GRAPIN, A.; DAMBIER, D.; NOYER, J.L.; LANAUD, C.; KAHL, G.; LAGODA, P.J.L. Molecular breeding in genus Musa: a strong case for STMS marker technology. Euphytica, Wageningen, v.96, n.1, p.49-63, 1997.

KOEHLER-SANTOS, P.; DORNELLES, A.L.C.; FREITAS, L.B. de. Characterization of mandarin citrus germplasm from Southern Brazil by morphological and molecular analyses. Pesquisa Agropecuária Brasileira, Brasília, v.38, n.7, p. 747-806, 2003.

LAGODA, P.J.L.; NOYER, J.L.; DAMBIER, D.; BAURENS, F.C.; GRAPIN, A.; LANAUD, C. Sequence tagged microsatellite site (STMS) markers in the Musaceae. Molecular Ecology, Oxford, v.7, n.5, p.657-666, 1998.

LEITE, J.B.V.; SILVA, S.O.; ALVES, E.J.; LINS, R.D.; JESUS, O.N. Caracteres da planta e do cacho de genótipos de bananeira, em quatro ciclos de produção, em Belmonte, Bahia. Revista Brasileira de Fruticultura, Jaboticabal, v.25, n.3, p.443- 447, 2003.

MANTEL, N. The detection of disease clustering and a generalized regression approach. Cancer Research, Baltimore, v.27, n.2, p.209-220, 1967.

MASCARENHAS, G. Análise do mercado brasileiro de banana. Preços Agrícolas, Piracicaba, n.134, p.4$12,1997$.

NING, S.P.; XU, L.B.; LU, Y.; HUANG, B.Z.; GE, X.J. Genome composition and genetic diversity of Musa germplasm from China revealed by PCR-RFLP and SSR markers. Scientia Horticulturae, Amsterdam, v.114, n.4, p.281-288, 2007.

NSABIMANA, A.; STADEN, J.V. Assessment of genetic diversity of Highland bananas from the National Banana Germplasm Collection at Rubona, Rwanda using RAPD markers. Scientia Horticulturae, Amsterdam, v.113, n.4, p.293-299, 2007.

OLIVEIRA, M.S.P. Caracterização molecular e morfoagronômica de germoplasma de Açaizeiro. 2005. $171 \mathrm{f}$. Tese (Doutorado em Genética e Melhoramento de Plantas) - Universidade Federal de Lavras, Lavras, 2005.

ORIERO, C.E.; ODUNOLA, O.A.; LOKKO, Y.; INGELBRECHT, I. Analysis of B-genome derived simple sequence repeat (SSR) markers in Musa spp. African Journal of Biotechnology, Joanesburgo, v.5, n.2, p.126-128, 2006.

ROHLF, F.J. Numerical taxonomy and multivariate analysis system. New York: Exeter Software, 2000. 38 p. Version 2.1 . 
SCOTT, A.J., KNOTT, M.A. A cluster analysis method for grouping means in the analysis of variance. Biometrics, Washington, v.30, n.3, p.507$512,1974$.

SILVA, S.O.; ALVES, E.J.; LIMA, M.B.; SILVEIRA, J.R.S. Bananeira. In: BRUCKNER, C.H. (Org.). Melhoramento de fruteiras tropicais. Viçosa-MG, v. 1,p. 101-157, 2002.

SILVA, S.O.; MORAIS, L.S.; SANTOS-SEREJO, J.A. Melhoramento genético de bananeira para resistência a doenças. In: ROMÃO, R.L.; RAMOS, S.R.R. (Ed.). Recursos genéticos vegetais no Estado da Bahia. Feira de Santana: UEFS, p.49-67. 2005.

SINGH, D. The relative importance of characters affecting genetic divergence. The Indian Journal of Genetics and Plant Breeding, New Delhi, v.41, n.1, p.237-245, 1981.

SOTO BALLESTERO, M. Banana: cultivo e comercialización. San José. Litografia y Imprensa, 1992. p. 170-204.
SOUZA, E.; SORRELLS, M.E. Relationships among 70 North American oat germplasms. II. Cluster analysis using qualitative characters. Crop Science, Madison, v.31, n.3, p.605-612, 1991.

VAZ PATTO, M.C.; SATOVIC, Z.; PÊGO, S.; FEVEREIRO, P. Assessing the genetic diversity of Portuguese maize germoplasm using microsatellite markers. Euphytica, Wageningen, v.137, n.1, p.63$72,2004$.

VIEIRA, E.D.; CARVALHO, F.I.F.; OLIVEIRA, A.C.; BENIN, G.;ZIMMER, P.D.; SILVA, J.A.G.; MARTINS, A.F.; BERTAN, I.; SILVA, G.O.; SCHMIDT, D.A.M. Comparação entre medidas de distância genealógica, morfológica e molecular em aveia, em experimentos com e sem a aplicação de fungicida. Bragantia, Campinas, v.64, n.1, p.51-60, 2005.

WANG, X.L.; CHIANG, T.Y.; ROUX, N.; HAO, G.; GE, X.J. Genetic diversity of wild banana (Musa balbisiana Colla) in china as revealed by AFLP markers. Genetic Resources and Crop Evolution, Dordrecht, v.54, n.3, p.1125-1132, 2007. 